\title{
Application of China Ancient Poetry Culture Art in the Interior Design in the Construction of Tourism
}

\author{
Yanchi Chen ${ }^{*}$
}

The Faculty of Arts, Xuzhou College of Industrial Technology, Xuzhou 221140, Jiangsu, China

\begin{abstract}
The culture of Chinese ancient poetry has always been a part of the extensive and profound Chinese history and culture. However, the culture of Chinese ancient poetry is not only confined to the field of literature, if it means in the interior design, starting from the overall design of the indoor environment, provide new perspectives and ways of thinking, stereo review and organization from the overall co-ordination. China ancient poetry and art technique of expression" into the theme of the hotel, way of literature art to create a space for "language, poetry and art technique of expression" abstraction and induction to the language environment of theme hotel interior design, is the study of considerable value and meaning, provides a new perspective of literature the research and design of the more abundant. This paper expounds the research background and significance, and then analyzes the origin of theme hotel in China and the development and current situation, theory of theme hotel is studied more deeply, including the characteristics of theme hotel with modern value, and summarizes the theme of the hotel to determine its theme and theme culture of the principle. Turisthotellet construction made a detailed and thoughtful positioning strategy. The theory of universal things related, geographical and cultural impact on the formation of China ancient poetry, and the means of artistic expression of China ancient poetry in the indoor space design, summarizes the common points of poetry and indoor, indoor space analogy expression artistic conception in poetry style. Research on China ancient poetry and art features, starting from the narrative poems and lyrics, mining poetry language characteristics and aesthetic characteristics of the common points and differences, for the next chapter analyzes the indoor space. To explain China ancient poetry theme hotel design concept in the actual project and application of methods, starting from the abstract and concrete from two aspects, the ancient poetry into the design concept through to the overall environment design and each functional space.
\end{abstract}

Keywords: Chinese ancient poetry culture, interior design, regional culture, theme hotel, the art of rhetoric.

\section{INTRODUCTION}

In 1943, American well-known social psychologist Maslow proposed "hierarchy of needs", after the gradual social and economic development and improve people, after the basic physical requirements are met, people will all aspects of daily life have a higher level of demand. The author thinks that, when people meet the basic conditions of material life, will pay more attention to the spiritual pursuit. Consumers in the purchase of products and services, to explore the cultural background, the depth of experience will become the leading product for the consumer demand. To make a reasonable market research on market segmentation based on this theory, investigated and analyzed through multiple levels of customer's desire to buy, own demand and consumption habit and ability. The goods we research into the market, from the consumer's different division of each market, so a reasonable position, for different consumers with different commodities and services that are usually positioned products known differences. Through the above analysis and research, then businesses and product design personnel must be targeted to different customers to make appropriate and with its own characteristics of the goods and services. In the course of the development of the reform and opening up, the development of social economy Chinese gradually [1], our theme hotel from scratch, all the features of theme hotel also emerge as the times require. In Shenzhen, there is a Venice culture as the theme of the Venezia Hotel; there is a full use of its three kingdoms culture as the theme of the Jing Chuan Hotel in Chengdu in Sichuan; in addition there are two known as the famous scenic area, Jiuzhaigou area and Qingchengshan scenic spot, the two scenic areas have not only the beautiful and unique natural scenery, and the profound religious culture, under the Jiuzhaigou scenic area of the Tibetan culture and local rendering, built the world famous Jiuzhai Paradise, the local culture and customs of the perfect combination, make people all praise, and is located in the scenic areas of Qingchengshan flying crane has the Taoism culture as the theme, the Taoist culture into the hotel, let the people from feel the vast beauty of the hotel and leisure culture. Located around the animal ecological park Chime Long Hotel Guangzhou times to wild animal theme [2]; Confucius hometown Qufu is the construction of Confucian culture theme hotel. And so on, the theme of the hotel as well as bamboo shoots after a spring rain as a place where. China's current theme hotel, regardless of level, decoration and cultural management, compared with the international theme hotel, there are still a considerable gap. (check the Statistical 
Yearbook) however, China is a developing country with a population of 1400000000 in the market, open Chinese is attracting global attention, foreigners have come to China investment or tourism, they are full of curiosity and respect for the history and culture of China. With the rapid development of tourism Chinese, no doubt will further promote the development of hotel industry, more accurate I release local history and characteristics of the theme hotel development is fast, emerge as the times require. Between 2004 and 2005 , the theme of the hotel in the two milepost type across china. The first time was in 2004 the capital of my country, in all positive efforts in China to set up the international theme hotel alliance [3], which is not only in China, a major breakthrough, but also the development of the international hotel industry paid a new page is the second time the following year; Jiangmen Guangdong Province in China held the first International Forum on the Forum on the theme culture, by the authority organization in our country at present the first batch of theme hotel award. Nevertheless, our theme hotel is still at the initial stage of development. From now to the future, we need to explore the road is still very long. Research shows that, the number of theme hotel in China increased dramatically in recent years, a lot of the hotel to change the general pattern, the theme into the hotel [4], so that more people have the preference of people can deeply feel to enjoy them. The industry also need to constantly explore, constantly sum up, and make unremitting efforts to accelerate the development and improve the level of it.

\section{THE RELEVANT THEORETICAL RESEARCH OF TURISTHOTELLET BUILDING}

\subsection{The Value and Characteristics of Turisthotellet Building}

Turisthotellet is the positioning of the orientation of culture. The Turisthotellet cultural positioning accuracy affects the development effectiveness of Turisthotellet. After careful consideration of the hotel designers to develop tourism Turisthotellet center after being launched, the work will be carried out to determine the travel around the multi angle multi range of tourism effect. For example, the internal and external decoration, hotel staff and other clothing and travel related services will strive to the extreme contrast hotel [5]. Therefore, the Turisthotellet must have their own unique and distinctive cultural tourism elements will be displayed.

The core competitiveness of the Turisthotellet is not exaggerated shape or special service. In order to make a success of the Turisthotellet, is bound to have great originality to the one and only, only to do the research in order to seize the initiative in the competition to Turisthotellet; the supporting services with in order to create a unique core competitiveness of Turisthotellet. That is needed is a deep cultural connotation. The cultural connotation, can be through a deep memory representation of people who watch the heart; it can be instantly into the design of a good cultural atmosphere. At the same time, we know from where to psychologists, for the consumer, the fastest and most direct way is through the eyes of consumption. Through the eyes to see to understand, whether it is a simple story or distant connotation can be the first time to be received by the surface expression of things. And the decoration decoration bring visual impact and cul- tural connotation, is a Turisthotellet in order to attract consumer attention effectively break the code, it is also the core competition of. Du Fu's cultural connotation is the cultural field of art to enjoy the luxury, the extension into the public eye is the visual perception [6]. Meet the need of the consumer products are not necessarily upscale atmosphere, on the grade, and perhaps, low-key luxury, has the connotation of.

As a hotel, must accord with the aesthetic needs of the people. Can't just unique, novel. Turisthotellet is give people a fresh feeling, but also through the form to the feeling of beauty. In addition to the hotel accommodation and catering service and comfortable and efficient, more should give people more beautiful enjoyment.

To create the cultural connotation, which is the Turisthotellet and the traditional sense of the hotel's different highlights. With the continuous development of market economy, the expansion of the hotel industry, the customer's taste is increasing. At this moment, as the hotel itself, must create their own brands to attract consumers [7]. The hotel is not merely to provide accommodation, but a continuation of products through its own changes, can become an integral part of the tourism industry eco chain, can even become a tourist culture.

The arrival of the new century, the cultural industry has become one of the most promising global industry. On the cultural industry itself, is in itself a from spirit to material process, the development of the whole society and operation are in fact depends on such a culture to the market resources, and resources from the market to gradually progressive process of culture. The design and im. The design and implementation of the Turisthotellet, the purpose is to meet the market demand of culture, but also the culture to market output. Through the unique local characteristics of the Turisthotellet, rapid and strong local culture into the market, and the Turisthotellet from the market feedback to the protection of the culture is more powerful. With vast territory and abundant resources Chinese billion plus people, is undoubtedly the economic future of the world's largest consumer market, is also the largest cultural consumption market.

\subsection{The Determine Subject Principle of Turisthotellet Building}

Through the analysis and investigation, combined with the needs of the market and consumer demand, combined with their own advantages to the full in the cultural area China ancient cottage; choose to China ancient poetry as Tianchen hotel tourism, is the connotation of tourism choice. After determining the tourism Turisthotellet, will require careful design process is complex and creative, from design to decoration room decoration to the corner, from a poem to a picture, from a cup to a dish, every step needs complete and systematic tourism context. On the other hand, the Turisthotellet itself, is independent of the individual, but also a part of the whole scenic composition. Therefore, the tourism elements inside the Turisthotellet will need to complement each other with the outside world the principle of certain area [8].

A, As a public building in the region, with Turisthotellet itself and the surrounding landscape, the overall image of the 
city and coordinate with each other so as to. Selection of tourism not only can be used as a hotel and tourism, should make the tourism has become one of the city's pronoun.

$\mathrm{B}$, the city as a complex combination of human life, the Turisthotellet as a special individual needs to meet the overall city planning in a given area. In both the hotel on the basis, for the transformation of the hotel, must be combined with the overall planning and consideration.

\section{ANALYSIS OF ANCIENT POETRY CULTURE CHINA TURISTHOTELLET BUILDING INTERIOR DESIGN FEASIBILITY}

China ancient history as Chinese great patriotic poet, his thoughts and feelings into the world of Confucianism was later spread so far. Keep the motherland in heart, mind and the world. So far in the development of the socialist China characteristics, this thought still has an important guiding significance. This positive energy to pass out of the deep thought not only affects each came to the cottage of tourists from around the world to read more of his poems patriot. His poetry and moral education is full of significance to today's education learning.

\subsection{The Artistic Conception of Ancient Poetry and the Actual Scene China Distribution}

Interior design is a look at the beauty of the United states. The United States is because of the change of environment and the vision to the heart, let a person a chain process to produce happy from the heart. While the interior of the conception is the overall impression of the senses and. Through the indoor artistic conception to convey the intent of the designer, make people resonate more deeply, to travel the rendering of artistic conception, to have the feeling of beauty. In China ancient poems, expressed the artistic conception in poetry through people's understanding of the artistic conception of the poetry. However, the indoor environment design and the difference that can be most quickly put the poetry mood expression for the guests to answer. Therefore, the conception of the shore was particularly important in interior design. The only conception and reasonable arrangement to give people the feeling of beauty. So combining emotion with scenery, do not spend too much time and energy to create artistic conception design hotel accept nature indoors.

\subsection{The Relationship Between Chinese Poetry Art and Interior Design}

Design of the indoor environment as a system, by the combination of many different functional units and the function and the significance, has the different units of the system to form a whole in the principle of form beauty and form under the guidance of the law. A space is the form, light, color, texture, lighting, furniture and furnishings, greening and other visual elements to each other and influence each other and form an inseparable organic whole, indoor space to display is the organic relations between the various objects in space are. In these factors influence each other, mutual restraint, and various design elements each contains the same or similar information. Such as color can adjust the indoor light intensity, color can improve the spatial scale and proportion, light can affect the visual texture, texture can change the sense of scale, the sense of space, a sense of weight and so on. Whether based on what kind of tourism, the design technique, excellent design although the thousands of group, but one thing is the same, it is reasonable to organize all kinds of elements of space, in order to reflect a harmonious beauty. Visible, the whole and the part of the interior design system is generally related to the. Poetry is the statement to describe things, this truth, which expresses the author reflects social and emotional art. A poet can respond to your own feelings through poetry, the statement to reflect the objective reality of the integration of refining.

The poet can through the grasp of rhetoric and rhythm of the poetry is more beautiful. The interior design of Turisthotellet is not only to the beauty of performance, but also to create the mood expressed by tourism. The same mood, the same poems give is to give people aesthetic feeling, the sense of beauty, whether it is from the literature, poetry, or a guest room design is from the same point of view to the feeling of beauty. The artistic conception of poetry through the text expression, language organization; interior design through the establishment of the overall planning and design and detail to complete the artistic conception. "The artistic conception of space refers to the space form of art spirit and the social culture and people's aesthetic consciousness, aesthetic experience and the spirit and the formation of the perception of [4]."

\subsection{The Interior Design of Turisthotellet Building Artis- tic Technique of Expression}

By the abstract image or idea to the specific things Lenovo, which is a symbol for the effect of suggestion. Symbol to express not only the individual things, give a person the overall mood. The way to create different design hotel interior artistic conception in the general literature conception, combined with the interior design conception of the need to understand the environment of art and decorative techniques, showing that the inherent meaning, create a set of artistic conception. Through the performance through association and that has reached the design effect.

When we see something in the day to day life, will naturally think of the things associated with them, such as see silly lazy koalas and majestic Sydney Opera House, we naturally think of australia. Or the most simple and direct, see a variety of instruments, we will have a corresponding contact, sometimes like a voice in the ear. See the flute is that the mind is at the piano resounded with music, which produced by the contrast between the nature and function of two things on the relationship between contact is called. In the indoor environment design conception, in contrast with the association, is not to let the experience feelings of the thing itself, but lies in strengthening the connection to reality and imaginary things influence each other, so as to show the combined experience, makes the experience more profound experience in the whole process.

In the design process of the indoor artistic conception, should also be a combination of factors point in a certain environment, the subjective emotion. Through the use of symbolism, combined with their own emotional factors which can effect prompt again. There is a good example in this application, that is "the Nanjing Massacre Memorial 
Hall", although the design itself is not a hotel, but also no shortage of symbolism, to bring people back to that period of history, people have a certain subjective emotional factors, those sad the tragic scenes, allowing visitors to not have a strong subjective feeling, at this point, the designer design also reflects the success.

There is an important way to the hotel interior design conception, method that is through literary works will be used to the thinking in image will be added to the existing building the artistic conception of the indoor environment. In this way, in the interior design is mainly through their inner thoughts or a a image of the overall indoor environment. For example, there is a company called Guangzhou day Crane Hotel, tourism in the design of atrium in the sunshine, natural landscape and a series of factors into the interior design after the first people thought was a simple landscape modeling, and then the ordinary landscape designers have made a certain ethnic characteristics, the relentless rockery water gives the hometown of meaning, not only to show the motherland mountains and rivers, the more people nostalgia emotion experience. This metaphor of the invisible is achieved combining emotion with scenery, scenes of the objective.

But these are relatively indirect ways and means. In the indoor environment atmosphere, the most simple and direct way is to express the ideological content directly through the language or art show in the room.

In the create indoor artistic process, will be for decoration applied to the frame or plaque. Then, the ideological content expressed by these frames. The plaque is the most direct expression of ideas. Rock engraved with the home and other related content, is undoubtedly caused by overseas Chinese or foreign travel to plot the most direct collision of ideas thought the most direct.

With the above three kinds of methods: symbol, metaphor, text to express hotel space artistic conception, summarizes the most important three points, one is the overall atmosphere of the space of the control, in the spatial arrangement of hotel indoor environment, the artistic conception into, such as the need to air out the profound feeling, can consider in the larger floor space second, the article to do; the direct expression of the organic combination and indirect infection, different rooms were analyzed, and then into the layout, will be followed by the words or pictures directly in a limited amount of decoration. Finally, embraced by three ways, the above results can guide us how to ancient poems into modern interior space, it has very strong applicability.

\section{ART OF ANCIENT POETRY CHINESE IN TUR- ISTHOTELLET IN ARCHITECTURE DESIGN IDEA AND OPERATION MODE}

\subsection{Like to Reflect the Principle of Application}

The most direct and effective way in the above there is a called "design techniques and tips", this is one way in the ancient style of decoration in the most commonly used, is the most widely used technique. Starting directly from the facade, regardless of is the lobby or room, even if it is a wall, but also through the calligraphy, painting works as a decoration. Poetry in the sentence plus related illustration has a very high cultural generality of ancient poetry.

\subsection{Abstract to Reflect the Principle of Application}

In fact, in addition to direct the original works of calligraphy poems as embodiment of tourism is a more direct way. Another way is relatively abstract, but no less influential than the first. That is the principle of the abstraction and representation. In Chinese ancient poems, there are many available poetry real remodeling. For example China ancient poem "spring night rain" "ye are the black cloud trails, river boat fire ming. You will see red is wet in heavy landscape, flower city. " The poems in the "ship", "fire", "red wet place", "flower" and other objects, to reproduce in landscape design. The interior design is not difficult.

\subsection{The Practical Application of Ideas}

In the design of the interior environment, need to have the breakthrough point of regional culture characteristics, and often can be used as a starting point the most ideal. Turisthotellet is a hotel, the hotel's function and use, the hotel needs good lighting and ventilation. So in the public areas of the hotel not only need to meet the needs of cultural connotation, but also to meet a transparent environment, so as to bring comfort and a point in the interior design of the hotel is also very important, it is the partition function. In the process of using, the partition function can directly affect the hotel's overall operational effectiveness.

Beauty is the beauty of artistic conception of poetry, beauty and form beauty of harmony and unity. Then there is what kind of style into the hotel? A quality suggestive of poetry or painting, is a kind of artistic life Tianchen building hope to the human experience. With the help of Du Fu's poems into the indoor environment in dyeing, let a person in a variety of experience and feel comfortable to enjoy the hotel's service at the same time from the variety of style and artistic conception of the. Confucianism in ancient Chinese, have their own life creed. At the same time, his own virtue also is influenced by the current effect. Today, the influence of his virtue and culture also has many positive effects on later generations.

\subsection{Artistic Expression China Poems}

From the Chinese ancient verse, people get a lot of inspiration. In the artistic conception of this category, Chinese ancient poems have been fully used. Examples of this be too numerous to enumerate, like Beijing, Chengde villa, a common water kiosk, is borrowed from the China in ancient poetry "water heart does not race, both care about the cloud later" artistic conception.

\section{THE PRACTICAL APPLICATION CHINA POETRY IN THE INTERIOR DESIGN OF TURISTHOTELLET BUILDING}

\subsection{Turisthotellet Lobby Design}

The design theme expresses the cultural characteristics of China poetry, make the hotel distinctive tourism which is China so far only to Chinese ancient poetry culture tourism Turisthotellet. Tianchen hotel close to five hundred square meters, including function area has a desk, lobby Rest Area, at the service desk behind a transparent glass corridor, as a tea room, Rest Area for guests to enjoy. In the planning of 
these functions at the same time, the contradiction of space and area by means of the method of open. At present, the transformation of the main consider the space and China ancient poetry culture combination.

Here used to Chinese ancient "Wang Yue" as a whole image to enter into, Tianchen Floor guests feel the concrete image. "Wang Yue" is the ancient North travel Chinese Qilu done (poetry, the original "Shandong Daizong husband how?. Good luck bell Shenxiu, yin and Yang Xiao cut faint. Swing chest raw stratus, I strain my sight after birds flying home. It Would be extremely Ling, the list of small hills ". This poem wrote the magnificent Taishan pick list, beautiful scenery, towering tall, also expressed the poet to praise and love the motherland beautiful rivers and mountains of a country. By this time, can show the poet to climb, not afraid of hard, overlooking all the lofty sentiments and aspirations, this conception is used to China ancient poetry culture tourism Tianchen building hotel lobby space can not be right.

The main lobby space color gray and Zhu Hong, brings a sense of calm in the overall tone, also express "Wang Yue" in the nature of Zhongshan love condensed Ling Shenxiu mood. "Top" as one of the most important design elements, the design thinking from the traditional "indoor" concept, which shows the sky, the lighting design for the auspicious clouds pattern. The walls on both sides of a display and ink pattern, to create the atmosphere, so that visitors to enter the feeling, "standing on the mountain", head for the sky, look for the mountain side. On both sides of the wall, and the ink and wash painting to achieve, through the LED screen flow, with the flow of time "sea of clouds", "sunrise" feeling. This outstanding poetry "chest swing stratus clouds in the mountains", emerge in an endless stream, mood swing forward to. The lobby with marble wall in front of living, is a visual view point, where the use of movable type printing the "Wang Yue" the whole poem presented, named space travel, let a person feel to Tianchen lobby to create poems in the atmosphere. "Wang Yue" and "Hope", is the essence of the spatial location, do not have a "look" writing the poem, but every sentence is in the description of mountains and rivers "Hope", from far to near, from North Korea to the evening. A description of the way this is Chinese ancient poetry art. For wall decoration, but also reflects the design style of decoration.

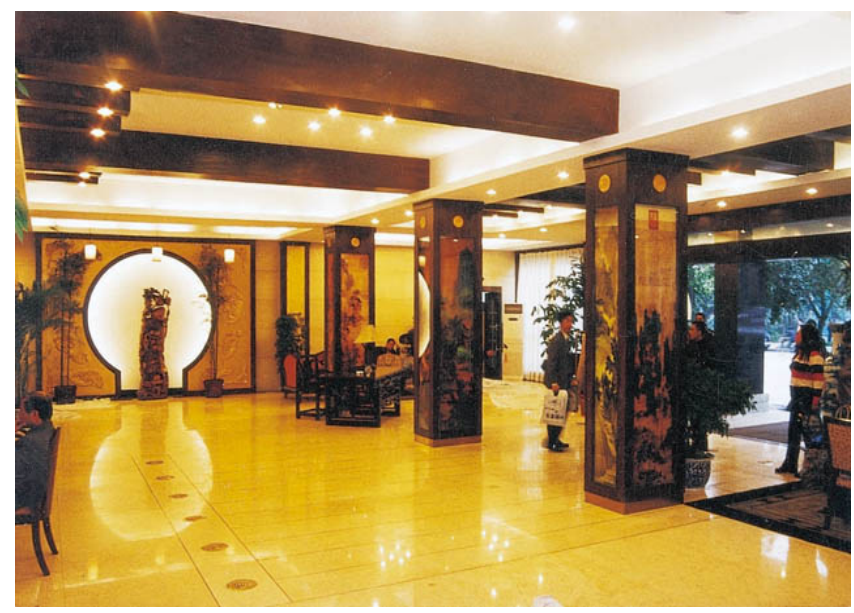

Fig. (1). The Lobby of the Turisthotellet.

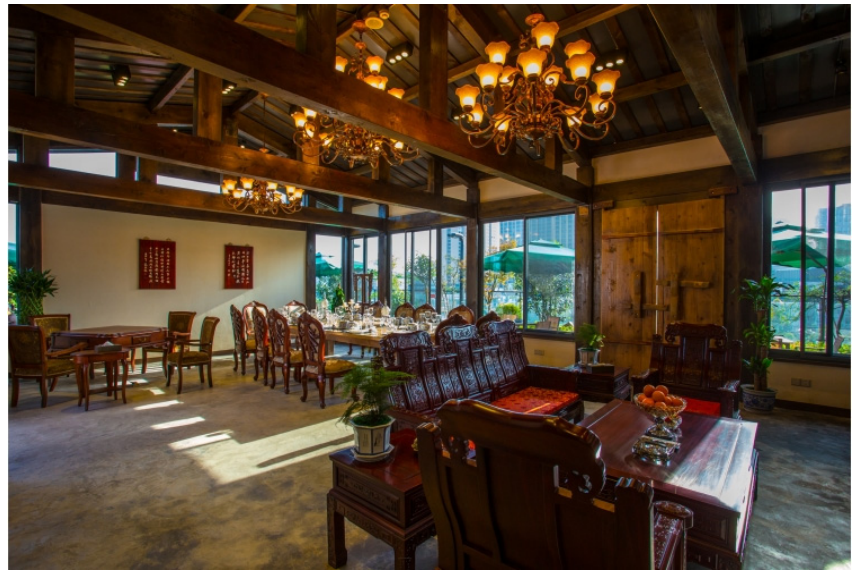

Fig. (2). The Design of Turisthotellet in the Pantry.

\subsection{Aisle Space Design}

The two and four floor of the corridors, walls are hung with modern calligraphy, ancient poetry Chinese everywhere, there are "quatrains", "high", "village", "flower" river in the "energy-saving" Chengdu famous poems, beautiful scene description Chinese with ancient, modern calligraphy hang the picture above, in the corridor walls. Hotel two to four layer the ground is a bright spot, children all over, it is worth noting that after patterns, wall paintings and calligraphy calligraphy echo each other at a distance, like a smooth stroke pattern, and made strong, sometimes thin pen. The corridor light source mainly comes from each room door with lights, and each picture of the lamp, the whole space appears in an elegant paper Ruzhi wind.

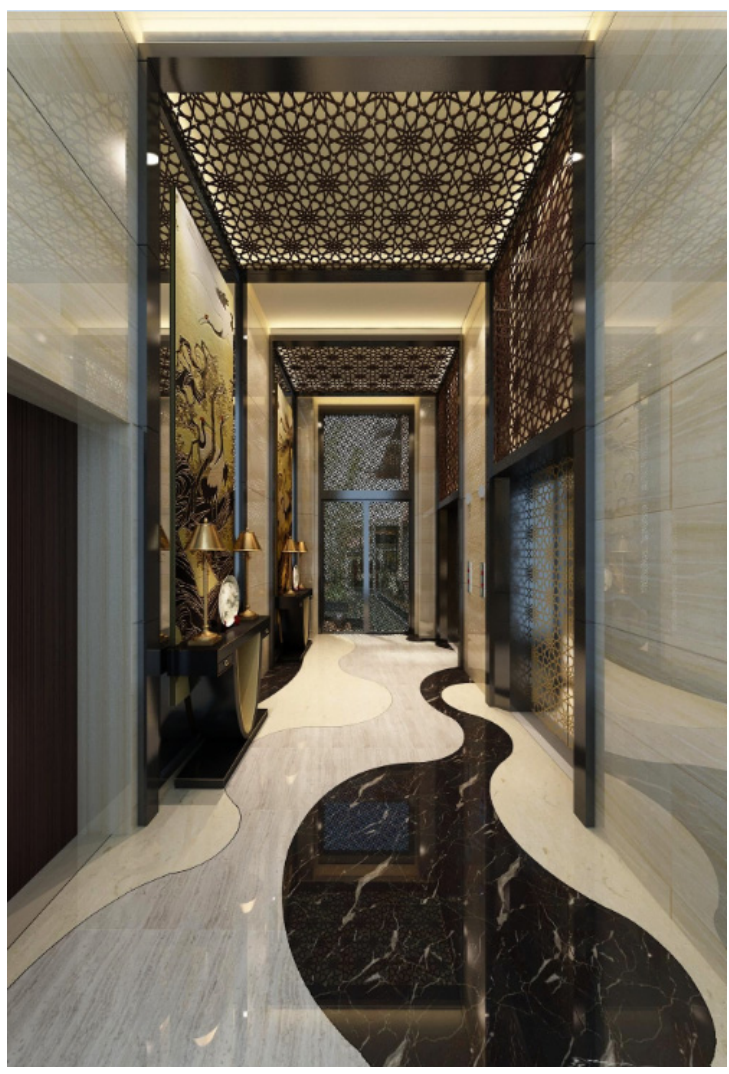

Fig. (3). The Design of Turisthotellet Corridor 1. 


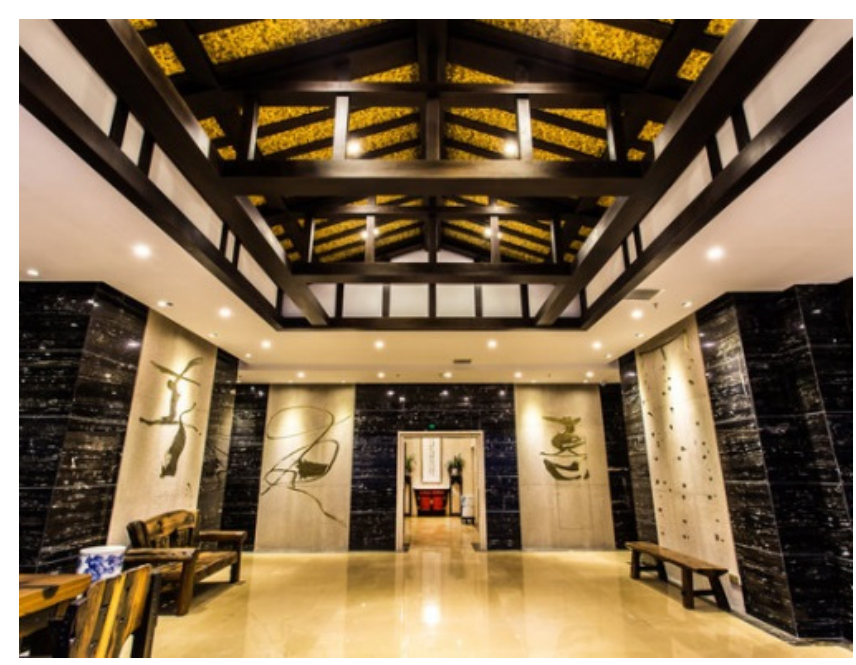

Fig. (4). The Design of Turisthotellet Corridor 2.

\subsection{The Design of the Hotel Rooms}

Standard rooms in hotel design is a highlight of the whole room reflects the simplicity of new Chinese style. To meet the functional requirements of the room at the same time, select some points, to reflect the Chinese ancient poetry culture. The room walls, the linen wallpaper, texture texture more sugar, but brings a close to nature feeling, similar to the rhetoric in poetry "Xing", and applies it to the interior, it is the China ancient cottage "cottage" artistic conception into interior environment. If guest room curtains and sofa sets, the materials used are the burlap, no any pollution. Say to the wall paintings, are similar to the guestroom corridors to write modern calligraphy of Chinese ancient poetry, or the ink image painting simple. Room ceiling with white latex paint, the ground uses more, taking into account the cost at the same time, the floor patterns also adds to the overall characteristics of the smart space, enhance the guest comfort. The room decoration, paper boxes, dressing mirror, luggage racks, cabinets, boxes, paper bags, including brush, plastic materials, has the style of lettering. Bed, wardrobe, lamp box, TV cabinets, doors have seats for veneer, echoing $\mathrm{Du} \mathrm{Fu} \mathrm{"cottage"} \mathrm{at} \mathrm{the} \mathrm{same} \mathrm{time,} \mathrm{will} \mathrm{also} \mathrm{"Andhra} \mathrm{Guang-}$ sha thousands, Great Jubilee the world famous all the land, immobilised" Wen Qi cleverly integrated into the whole space. Now, here is the "thousand million", Tianchen Hotel brought this home to the guests, "the mountain" place for guests to enjoy and relax settled.

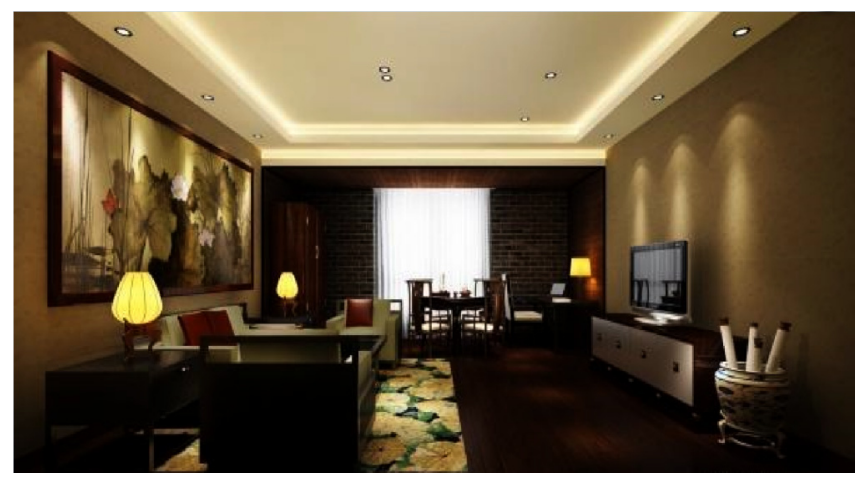

Fig. (5). The Design of Turisthotellet Room.

\section{CONCLUSION}

Turisthotellet can have today's development, and many other industries, will encounter a variety of opportunities and challenges of development at the same time, will also face the threat of various factors. The author thinks that the hotel managers must first recognize the strengths and weaknesses of the hotel itself, so that we can learn from each other, play their own advantages, make up their own shortcomings; it also should be vigilant in peace time, ahead of market survey and positioning itself, ready to meet the challenges and opportunities may come at any time; the second is how to build the core the author believes that the competitiveness of the hotel, many of the ideas, will form a lot of behavior, behavior in order to develop a habit, habit can be formed at many culture, that is to say culture originates from habit, custom originates from the behavior, the behavior stems from the ideological understanding, culture is difficult to copy, the culture is the core competitiveness of the hotel to! Get an invincible position in the industry, must have its unique core competitiveness, the Turisthotellet, the culture is the core competitiveness. Tianchen Turisthotellet, now is already China ancient poetry culture broad and profound implication, tolerance and poetry in the hotel as its core values. Hotel managers, practitioners should make oneself an example, from the behavior to industry standards to the ideology should be to complement each other, make rustic style hotel in the humanities and the mutual coordination, mutual fusion. This paper focuses on the decoration, decoration in the interior of the efforts, the Chinese ancient poetry culture by means of visual expression, the actual fusion to Tianchen building Turisthotellet. IPractice has proved that the hotel after the transformation of the management effect and the customer response is good. The author thinks that, facing the complex and changing times, the Turisthotellet will, good cultural tourism brand, tourism not only need to attract the attention of consumers, but also need to lay a solid foundation, make a long-term planning; not only to improve the established tourism, but also in the innovation of the existing tour to make better, these will affect the Turisthotellet development and success of the future. External decorative techniques and materials can be copied, can even The students surpass the teacher., in order to truly based on the Turisthotellet market, will need more inner thoughts to guide the hotel products, corporate culture, brand, service and management, is the core competitiveness. At the same time, designers and hotel managers also need to complement each other, more focus on its tourism and hotel products and services supporting the introduction of tourism elements, can be varied so that consumers feel a complete set of Turisthotellet service to more powerful market share. Tianchen hotel after determining the poems of tourism culture in ancient China, to create "Houde said, the core value of inspirational Tianchen" concept. The core values is the real meaning of tourism Turisthotellet, the hotel is also the guiding ideology, it is also the future development of a solid foundation for the hotel.

\section{CONFLICT OF INTEREST}

The author confirms that this article content has no conflict of interest. 


\section{ACKNOWLEDGEMENTS}

Declared none.

\section{REFERENCES}

[1] F. Yu, "Chengdu Regional Theme Hotel Design And Research," Master Thesis in Southwest Jiao Tong University, 2010.

[2] Z. Du, O. Yang, and Z. Chenghu, "Understanding of and thinking over geographical regionalization methodology. "Acta Geographica Sinica, vol. 63, no. 6, pp. 563-573, 2008.

[3] J.R. Maier, G.M. Fadel, and D.G. Battisto, "An affordance-based approach to architectural theory, design, and practice." Design Studies, vol. 30, no. 4, pp. 393-414, 2009.
[4] Y. Yang, Southwest Jiao Tong University Graduate Degree Thesis Interior Design Holography, 2007.

[5] J. Chen, "The ancient poems," Nanjing Forestry University Graduate Master's Degree Thesis of Modern Interior Design, 2008.

[6] H. Li, "Theme Hotel Public Space Design and Research," Master Thesis Southwest Jiao Tong University, 2007.

[7] H. Zhu, "The Theme Hotel Design in the Cultural Features," Master's Degree Thesis Kunming University of Science and Technology, 2013.

[8] H. Kong, and C. Cheung, "Hotel development in China: a review of the English language literature." International Journal of Contemporary Hospitality Management, vol. 21, no. 3, pp. 341$355,2009$.

Received: June 10, 2015

Revised: July 29, 2015

Accepted: August 15, 2015

(C) Yanchi Chen; Licensee Bentham Open.

This is an open access article licensed under the terms of the (https://creativecommons.org/licenses/by/4.0/legalcode), which permits unrestricted, noncommercial use, distribution and reproduction in any medium, provided the work is properly cited. 